\title{
Investigation on the Factors Affecting the Temperature in Urban Distribution Substations and an Energy-Saving Cooling Strategy
}

Fan Yang ${ }^{1, *}$, Wei $\operatorname{Ran}^{1}$, Tao Chen ${ }^{2}$ and Xiaochu Luo ${ }^{2}$

1 State Key Laboratory of Power Transmission Equipment \& System Security and New Technology, Chongqing University, 400030, Chongqing, China; E-Mail: 406961899@qq.com

2 Chongqing Electric Power Test \& Research Institute, Huangshang Road, Yubei District, 401123, Chongqing, China; E-Mails: chentaocqep@yahoo.cn (T.C.); 1xccqep@yahoo.cn (X.L.)

* Author to whom correspondence should be addressed; E-Mail: yangfan@cqu.edu.cn; Tel.: +86-13996289198.

Received: 8 December 2010; in revised form: 16 January 2011 / Accepted: 14 February 2011 / Published: 16 February 2011

\begin{abstract}
The different locations of the equipment in urban distribution substations (DSSs) and the location of inlet holes and outlet holes usually result in different ventilation effect, which means the power consumed by any ventilating devices present is different. In this paper the temperature field distribution in an urban distribution substation with different locations of the equipment in the substation was calculated first, then factors influencing the temperature field distribution were investigated, and the influence of the different factors was analyzed. When the distance between the apparatus and walls exceeds $3 \mathrm{~m}$, the change of the temperature in the DSS is very small. Therefore considering the floor area of the DSS, $3 \mathrm{~m}$ is the best value of the distance between the apparatus. With the change of the environment temperature or the velocity of the ventilation fans, the maximum temperature in the DSS or apparatus will change. Hence an energy saving ventilation strategy is proposed in the paper, and an intelligent cooling control system is developed, which can modify the velocity of the ventilation fans according to the environment temperature, and thus realize energy savings.
\end{abstract}

Keywords: distribution substation; dry-type transformer; temperature field; energy-saving 


\section{Introduction}

Final use energy reduction is an increasingly important topic in electrical engineering, and many experts have concentrated on methods to increase the usage of resources or strategies to save energy. With the development of cities in China, more and more urban distribution substations (DSSs) have been built for the supply of power to residential communities, and dry-type transformers are used more frequently in urban distribution substations due to their advantages compared with oil-filled transformers [1,2], such as small size, light weight, less space occupation, and above all, it adoption of epoxy resins with high temperature resistance as dielectric. However the heat conduction performance of dry-type transformers is worse, which results in a high temperature of the internal winding, and heat transfer occurs in the distribution substation. In addition, the high voltage (HV) switchgears and bus bars in the distribution substation also produce heat losses, which results in a temperature increase in the distribution house.

For the safety and high efficiency operation of dry-type transformers and HV switchgears in the DSS, a cooling system is usually installed to lower the temperature as otherwise the performance and reliability of the dry-type transformers will decrease. When the average temperature in the DSS increases by $1{ }^{\circ} \mathrm{C}$ above the standard average temperature $\left(35^{\circ} \mathrm{C}\right)$, the continuous working current of the dry-type transformer would be reduced by $1 \%$ [3]. It is suggested that the air temperature should not be higher than $45{ }^{\circ} \mathrm{C}$ in a DSS, and the difference between the temperature at the air-inlet and air-outlet should not exceed $15{ }^{\circ} \mathrm{C}$, and the average temperature in the DSS should not exceed $40{ }^{\circ} \mathrm{C}$. Consequently the following heat dissipation measures are frequently used in DSSs [4]: (1) installation of air conditioners; (2) increasing the floor area; (3) use of ventilating fans. Measures (1) and (3) consume power and (2) is wastes land, so it is necessary to evaluate the efficiency of current measures and develop a more energy-conserving ventilation strategy for urban DSSs.

In the paper, a model of a DSS in Chongqing (containing two dry-type transformers and switchgears) was set up first, and the temperature field distribution was calculated. Then factors influencing the temperature field distribution were studied, and the influence of different factors was computed and discussed. When the distance between the apparatus and wall exceeds $3 \mathrm{~m}$, the temperature change in the DSS is very small. Therefore considering the floor area of the DSS, $3 \mathrm{~m}$ is the best between the apparatus. With any change of the environment temperature or the velocity of the ventilation fans, the maximum temperature in the DSS or apparatus will change, therefore an energy saving ventilation strategy is proposed in this paper, and an intelligent cooling control system is developed, which can modify the wind velocity of the ventilation fans according to the environment temperature, which can result in energy savings.

The remainder of the paper is organized as follows: Section 2 presents the calculation of temperature field in the DSS, including the setup of model, calculation of heat losses in the transformers and switchgears, and setting of boundary conditions. Section 3 will describe the study on the factors influencing the heat distribution. This section also shows the influence on the distribution of temperature field caused by different factors. The intelligent cooling control system for urban DSS mentioned in this paper will be explained in Section 4. Finally, concluding remarks will be given in Section 5. 


\section{Calculation of the Temperature Field in an Urban Distribution Substation}

\subsection{Physical Model Setup}

A DSS in Chongqing is taken as an example for the study. In this DSS there are 2 dry-type transformers, two HV switchgears and a few bus bars. Because the heat loss on the bus bars is much less than the loss in the dry-type transformers and HV switchgears, therefore, to simplify the calculation, the bus bars were ignored in the model, as shown in Figure 1.

Table 1 shows the dimensions of the model. The dry-type transformer is a SCB10-1250/10 type, with a rated capacity of $1250 \mathrm{kVA}$, high-voltage side of $10.5 \mathrm{kV}$, low-voltage side of $0.4 \mathrm{kV}$, load loss of $9300 \mathrm{~W}$, and no-load loss of $2500 \mathrm{~W}$. For the HV switchgears, the total loss is $560 \mathrm{~W}$. The distance between the transformer and the HV switchgear is $12 \mathrm{~m}$, the distance between two transformers is $9 \mathrm{~m}$. The air inlet and the two transformers are located in the same line. In the calculation, the environmental temperature is $38^{\circ} \mathrm{C}$.

Figure 1. Physical model of the DSS (two transformers, two HV switchgears, one air inlet and two air outlets are considered in the model).

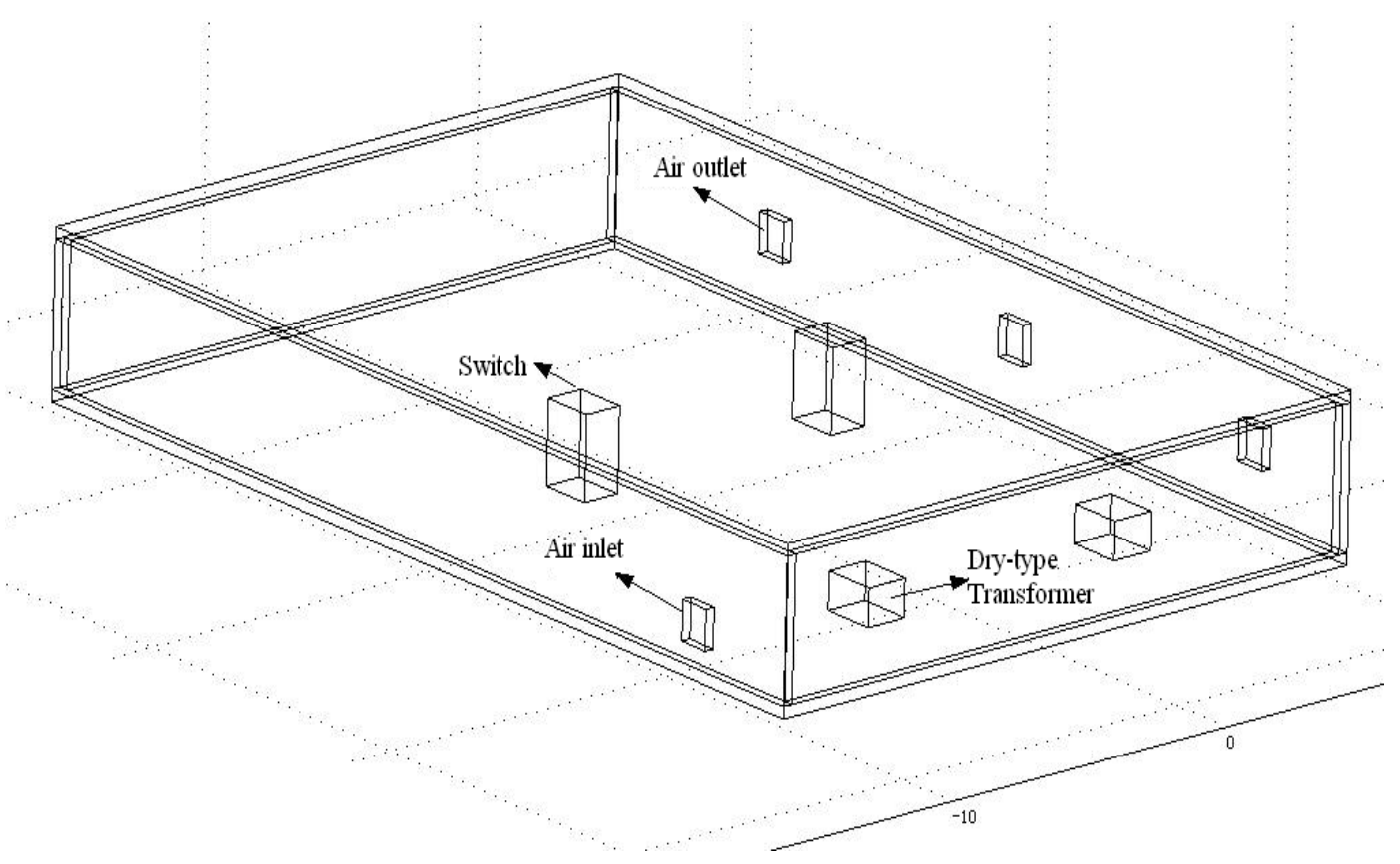

Table 1. Size of objects in the model.

\begin{tabular}{cc}
\hline Name & Size (Length, Width, Height) \\
\hline DSS house & $20 \mathrm{~m} \times 10 \mathrm{~m} \times 3.6 \mathrm{~m}$ \\
Transformer & $1.67 \mathrm{~m} \times 1.34 \mathrm{~m} \times 0.95 \mathrm{~m}$ \\
Switchgear & $1.62 \mathrm{~m} \times 1.23 \mathrm{~m} \times 1.81 \mathrm{~m}$ \\
\hline
\end{tabular}

\subsection{Heat Produced by Dry-Type Transformer}

Heat produced by a transformer in operation per unit time is just the total loss $(P)$ of the transformer, which includes the no-load loss $\left(P_{0}\right)$ and load loss $\left(P_{\mathrm{e}}\right)$. The no-load loss is a constant, and the load loss is equal to the square of the load rate [defined as the ratio of the current in low-voltage 
side $(I)$ to that in high-voltage side $\left(I_{\mathrm{e}}\right)$ multiplied by the load loss at rated load. That is:

$$
P=P_{0}+\left(\frac{I}{I_{e}}\right)^{2} P_{e}
$$

\subsection{Heat Dissipation of Apparatus in the DSS}

The main modes of heat dissipation of the transformers and switchgears in the DSS include heat radiation and heat convection. Heat convection includes natural-convection and forced-convection $[5,6]$. The natural-convection heat transfer occurs mainly on the surface of the switchgears and transformers without exposure to ventilating fans. The forced-convection heat transfer occurs mainly within the radiation range of the ventilating fans.

(1) Heat radiation transfer:

If the wall temperature is $T_{\mathrm{w}}$ and the environmental temperature is $T_{\mathrm{f}}$, then the heat quantity of the heat radiation transfer can be calculated as follows:

$$
\Phi_{r}=5.67 A_{r} \varepsilon\left(\left(\frac{T_{w}}{100}\right)^{4}-\left(\frac{T_{f}}{100}\right)^{4}\right)
$$

where $A_{\mathrm{r}}$ is the area of radiation surface $\left(\mathrm{m}^{2}\right), \varepsilon$ is the radiance on the radiation surface. For common steel plate, $\varepsilon=0.820$.

(2) Heat convection transfer:

The heat quantity of heat convection can be calculated according to Equation (3):

$$
\Phi_{c}=h A\left(T_{w}-T_{f}\right)
$$

where:

$h$ is coefficient of the heat convection, here $h=\frac{\lambda N u}{l}$;

$\Phi_{c}$ is heat quantity of the heat convection (W);

$N_{\mathrm{u}}$ is Nusselt number characterizing the property of the heat convection;

$l$ is characteristic length;

$\lambda$ is heat conductivity of air $\left(\mathrm{W} \cdot \mathrm{m}^{-2} \cdot \mathrm{K}^{-1}\right)$;

$A$ is area of the heat convection $\left(\mathrm{m}^{2}\right)$;

$T_{\mathrm{w}}$ is wall temperature $\left({ }^{\circ} \mathrm{C}\right)$;

$T_{\mathrm{f}}$ is air temperature $\left({ }^{\circ} \mathrm{C}\right)$;

For the natural-convection heat transfer:

$$
N u_{n}=C\left(G_{r} P_{r}\right)^{n}
$$

where $P_{\mathrm{r}}$ is the Prandtl number, $G_{\mathrm{r}}$ is the Grashof number, $C$ and $n$ are constants.

The natural convection occurring on the surface of the dry-type transformer can be regarded as the natural convection occurring on a vertical plate in infinite space. The values of $C$ and $n$ in Equation (4) are shown in Table 2. 
Table 2. Value of $C$ and $n$ for natural convection occurring on vertical plate in infinite space.

\begin{tabular}{cccc}
\hline Flow Pattern & $\boldsymbol{C}$ & $\boldsymbol{n}$ & Application Scope of $\boldsymbol{G}_{\boldsymbol{r}}$ \\
\hline laminar flow & 0.59 & 0.25 & $1 \times 10^{4} \sim 3 \times 10^{9}$ \\
transient state & 0.0292 & 0.39 & $3 \times 10^{9} \sim 2 \times 10^{10}$ \\
turbulence flow & 0.11 & $1 / 3$ & $>2 \times 10^{10}$ \\
\hline
\end{tabular}

For the forced-convection heat transfer occurring on the surface of the apparatuses, $N_{u f}$ can be calculated as follows:

$$
N u_{f}=C R_{e}^{n}
$$

where $R_{e}=u l / v, R_{e}$ is the Reynolds number, $u$ is the air velocity $(\mathrm{m} / \mathrm{s})$, and $v$ is the kinematic viscosity (in $\mathrm{m}^{2} / \mathrm{s}$ ). The values of $C$ and $n$ refer to the values in [4], which are obtained from wind-tunnel tests.

\subsection{Control Equations}

The temperature field inside the DSS is a temperature field containing heat sources, so the control equation can be formulated as follows [7,8]:

$$
\frac{\partial^{2} T}{\partial x^{2}}+\frac{\partial^{2} T}{\partial y^{2}}+\frac{\partial^{2} T}{\partial z^{2}}+q_{v}=0
$$

where $q_{v}$ is the heat rate in unit volume.

\subsection{Setting of the Boundary Conditions}

For the steady-state temperature field calculated in this paper, the boundary condition for convection is the typical second boundary condition. That is:

$$
-\lambda \frac{\partial T}{\partial n}=\alpha\left(T_{w}-T_{f}\right)
$$

For this model, the calculated equivalent heat source of the transformer is $220.93 \mathrm{~W} / \mathrm{m}^{3}$, and the equivalent heat source of a $\mathrm{HV}$ switchgear is $166.36 \mathrm{~W} / \mathrm{m}^{3}$. The convection heat transfer coefficient is 10.87 when the wind velocity is $5.55 \mathrm{~m} / \mathrm{s}$. The radiation factor is 0.6 . Considering the hot summers in Chongqing, an environmental temperature of $38^{\circ} \mathrm{C}$ is assumed in this model.

\subsection{Distribution of the Temperature Filed in the Objective DSS}

Ventilation fans were installed in the DSS shown in Figure 1. The parameters of the intake fan are as follows: the rotational speed $(n)$ is $1450 \mathrm{r} / \mathrm{min}$, the wind rate is $6178 \mathrm{~m}^{3} / \mathrm{h}$, and the wind pressure is $138 \mathrm{~Pa}$. The wind rate of the exhaust fans is $2000 \mathrm{~m}^{3} / \mathrm{h}$. According to the boundary conditions mentioned above the temperature field distribution in the DSS was computed, and the result is shown in Figure 2. The maximum temperature of the transformers and the switchgears is $60.829{ }^{\circ} \mathrm{C}$, and the maximum temperature of the air in the DSS is $40.057{ }^{\circ} \mathrm{C}$, which means the transformers and switchgears are under safe operation conditions. 
At present the ventilating fans operate day and night to ensure the apparatus operate safely, however the environmental temperature decreases during the night, so if same ventilating fans were used during the daytime and at night or during different seasons, energy waste will result when the environmental temperature is lower than the temperature in summer. Hence it is necessary to find an intelligent strategy for the cooling system. For this purpose, first of all, the factors affecting the distribution of temperature field in the DSS were investigated.

Figure 2. Temperature field distribution in the studied DSS.

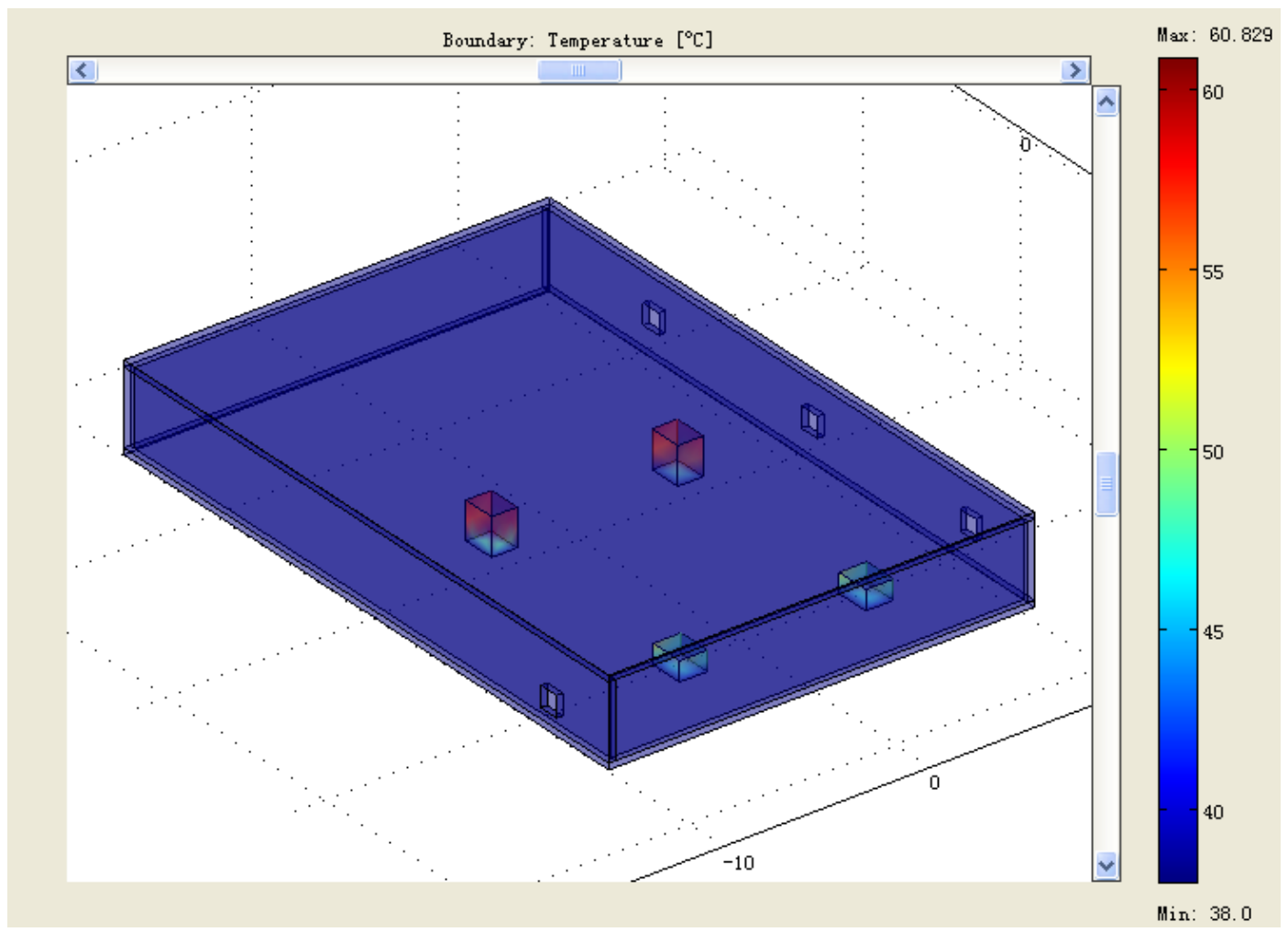

\section{Factors Influencing the Temperature Field Distribution in the DSS}

\subsection{Distance between the Apparatus and Walls}

Considering the conservation of land resources, the smaller the floor area of the DSS is the more land is saved. However, if the floor area of the DSS is too small, the distance between apparatus and the distance between the apparatus and walls inside the DSS will be reduced. When the distances are too small, the heat dissipation will be affected, and higher temperatures will result in the apparatus.

Therefore, in this paper, the temperature field distribution in the DSS with different distances between the apparatus and walls was calculated. Figure 3 shows the schematic diagram of the models with different distance between the apparatus and walls. Figure 4 shows the maximum temperature inside the apparatus and the substation with different distances between the equipment and the wall. In the calculations, the wind velocity is $2.5 \mathrm{~m} / \mathrm{s}$, and the distance between the apparatus and walls gradually increases from $0.3 \mathrm{~m}$ to $5.0 \mathrm{~m}$.

It can be seen from Figure 4 that the maximum temperatures inside the apparatus and the substation are decreasing gradually. The larger the distance between the apparatus and the wall is, the better the 
effectiveness of the heat dissipation is. When the distance between the apparatus and wall exceeds $3 \mathrm{~m}$, the change of the temperature in the DSS is very small. Therefore, as to the DSS computed in this paper, the distance between the apparatus should be more than $3 \mathrm{~m}$, and considering the floor area of the DSS, $3 \mathrm{~m}$ is the best value.

Figure 3. Schematic diagram of the models with different distances between the apparatus and wall.

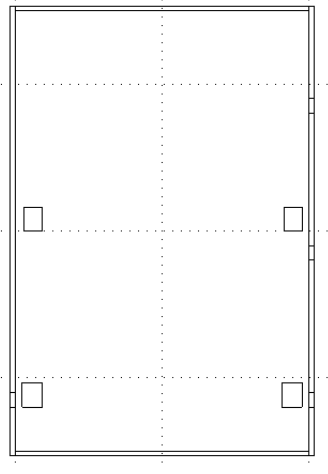

(a) $\mathrm{d}=0.3 \mathrm{~m}$

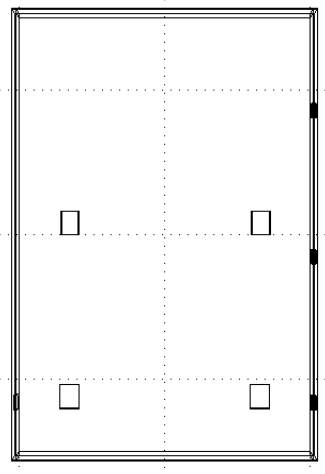

(b) $\mathrm{d}=3 \mathrm{~m}$

Figure 4. Maximum temperature inside the apparatus and the substation with different distances between apparatus and wall (wind velocity is $2.5 \mathrm{~m} / \mathrm{s}$ ).

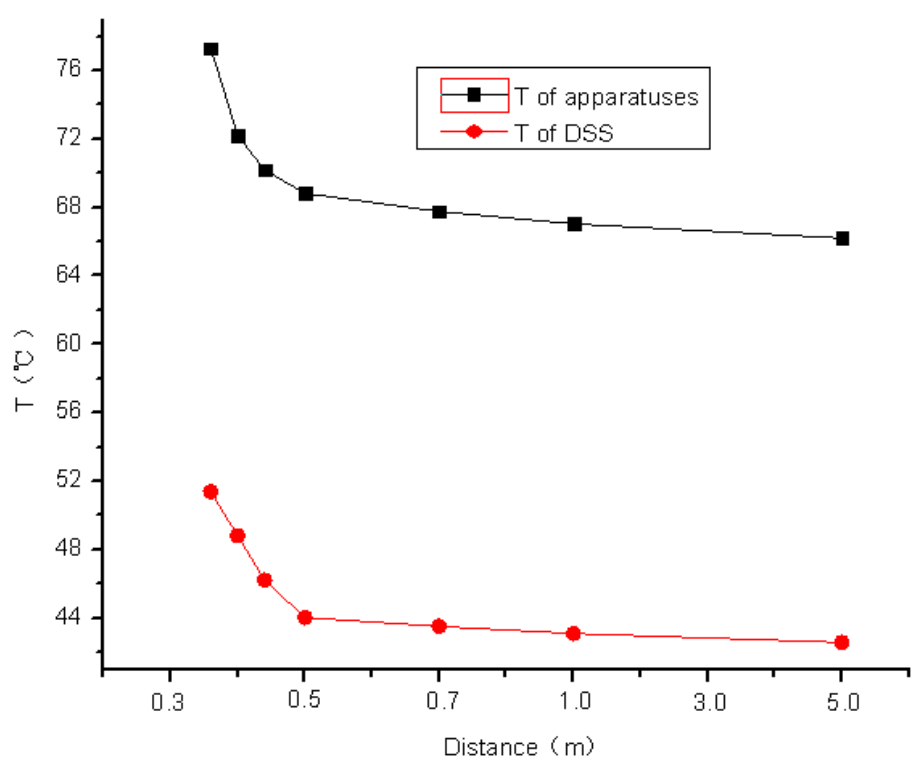

\subsection{Wind Velocity of Ventilation Fans}

The wind rate of fan is mainly decided by the wind velocity. Different wind velocities will result in different coefficients of convection heat transfer on the surface of switchgears and transformers. Consequently, the heat dissipation of the apparatus will also be influenced. Table 3 shows the temperature field distribution in the DSS with different wind velocities. It can be seen from this data that the wind velocity has a great influence on the temperature field distribution in the DSS. As to the indoor substation studied in this paper, when the wind velocity is $2.5 \mathrm{~m} / \mathrm{s}$, the maximum temperature in 
the indoor substation is $42.577^{\circ} \mathrm{C}$, which is lower than $45^{\circ} \mathrm{C}$. The condition for the safe operation of equipment is satisfied.

Table 3. Maximum temperature inside the apparatus and the DSS with different wind velocities (distance between apparatus and walls is $5 \mathrm{~m}$, environmental temperature is $38^{\circ} \mathrm{C}$ ).

\begin{tabular}{ccc}
\hline $\begin{array}{c}\text { Wind Velocity } \\
(\mathbf{m} / \mathbf{s})\end{array}$ & $\begin{array}{c}\text { Maximum Temperature } \\
\text { in the Apparatus }\left({ }^{\circ} \mathbf{C}\right)\end{array}$ & $\begin{array}{c}\text { Maximum Temperature } \\
\text { of Air in the DSS }\left({ }^{\circ} \mathbf{C}\right)\end{array}$ \\
\hline 1.0 & 72.835 & 46.386 \\
2.5 & 66.215 & 42.577 \\
5.0 & 62.131 & 40.813 \\
\hline
\end{tabular}

\subsection{Environmental Temperature}

Table 4 shows the maximum temperature inside the apparatuses and air in the DSS with different environmental temperatures when the distance between apparatus and wall is $5 \mathrm{~m}$ and the wind velocity is $2.5 \mathrm{~m} / \mathrm{s}$. It can be seen from Table 4 that the maximum air temperature in the DSS increases as the environmental temperature increases, therefore, considering the final use energy reduction, different cooling measures should be used for different environmental temperatures.

Table 4. Maximum temperature inside the apparatus and the substation with different environmental temperature (distance between apparatus and wall is $5 \mathrm{~m}$, wind velocity is $2.5 \mathrm{~m} / \mathrm{s})$.

\begin{tabular}{ccc}
\hline $\begin{array}{c}\text { Environmental } \\
\text { Temperature }\left({ }^{\circ} \mathbf{C}\right)\end{array}$ & $\begin{array}{c}\text { Maximum Temperature in } \\
\text { the Apparatus }\left({ }^{\circ} \mathbf{C}\right)\end{array}$ & $\begin{array}{c}\text { Maximum Temperature of } \\
\text { Air in the DSS }\left({ }^{\circ} \mathbf{C}\right)\end{array}$ \\
\hline 10 & 56.548 & 36.041 \\
20 & 61.129 & 39.281 \\
25 & 63.847 & 41.330 \\
30 & 66.215 & 42.577 \\
\hline
\end{tabular}

\section{Intelligent Cooling Control System}

According to the influence of the environmental temperature on the temperature field distribution in the DSS shown in Figure 1, an intelligent cooling control system was set up, and an energy-saving ventilation strategy was implemented, which means that for different environment temperatures, the wind velocity of the ventilation fan is different. This energy-saving cooling strategy is shown in Table 5, while Figure 5 shows the schematic diagram of the system.

As shown in Figure 5, the control system is composed of a central sever and a control terminal. A temperature sensor was used to measure the environmental temperature, and according to the measured environmental temperature, the MCU modifies the velocity of the ventilating fans in operation, hence for different environment temperatures the power-consumption for the ventilation fans is different, which can save energy compared with the current strategy, in which the ventilating fans always operate at the same velocity. The operational status of the apparatus are sent to the central sever by GPRS. This intelligent control system is now in operation in this DSS. 
Table 5. Energy-saving cooling strategy.

\begin{tabular}{cc}
\hline Environment Temperature $\left({ }^{\circ} \mathbf{C}\right)$ & Wind Velocity $(\mathbf{m} / \mathbf{s})$ \\
\hline 10 & 1.7 \\
20 & 2.3 \\
30 & 4.6 \\
38 & 5.5 \\
\hline
\end{tabular}

Figure 5. Schematic diagram of the intelligent cooling control system.

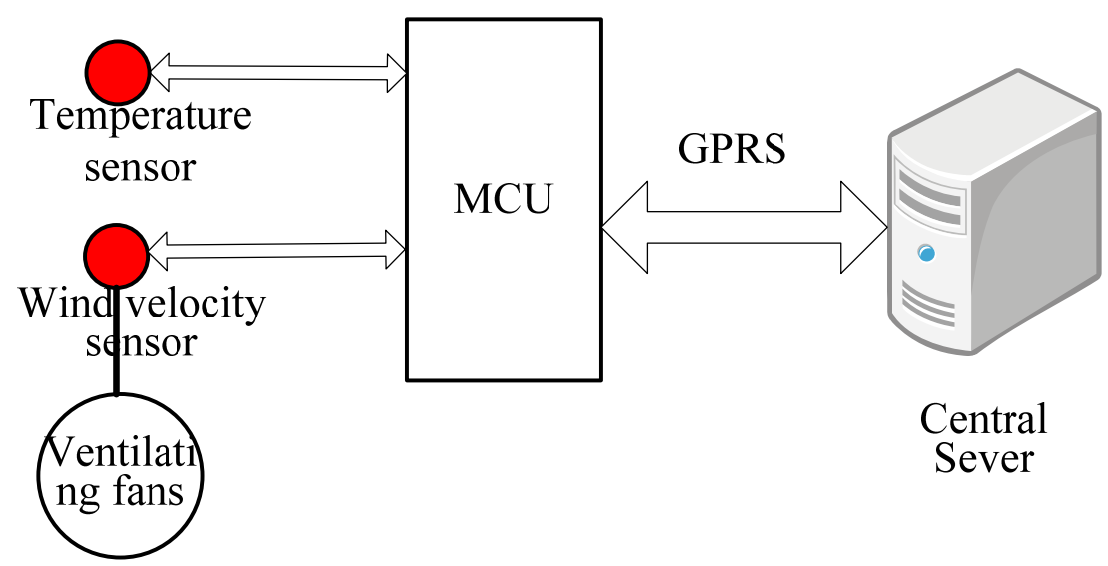

\section{Discussions and Conclusions}

A method to calculate the temperature field distribution in an urban DSS is proposed in this paper. The temperature field distribution in the DSS is calculated, and factors affecting the temperature in the DSS are analyzed, and finally an energy-saving strategy is presented.

Based on the results obtained in this paper, it can conclude the following:

(1) For the design of a new urban DSS, the size of the substation house and the distance between apparatus and walls should be calculated according to the parameters of the transformers and switchgears, and if there are too many bus bars in the DSS, the influence of these bus bars must be taken into account too. In this case the new DSS can occupy less space while having good ventilation efficiency. The design should not be made only according to the prior experience.

(2) As for DSSs already in use, an energy-conservation strategy should be implemented. For example an energy-conservation strategy can be based on the influence of the environmental temperature.

\section{Acknowledgement}

The authors would like to acknowledge the grant from the Fundamental Research Funds for the Central Universities (Project No. CDJZR10150001), the grand from Scientific Research Foundation of State Key Lab. of Power Transmission Equipment and System Security (Project No. 2007DA10512710502) and the grant from the National Natural Science Foundation of China (Project No. 51007096). 


\section{References}

1. Nochumson, C.J. Considerations in Application and Selection of Unit Substation Transformers. IEEE Trans. Ind. Appl. 2002, 38, 778-787.

2. Yuen, D.C.M.; Choi, V.; Liu, Z.G. The first $110 \mathrm{kV} / 35 \mathrm{kV}-31.5$ MVA cast resin transformer. IEEE Conf. Ind. Appl. 2004, 2, 763-767.

3. IEC. Electrical Installations of Buildings-Part 5-51: Selection and Erection of Electrical Equipment-Common Rules; International Electrotechnical Commission: Geneva, Switzerland, 2005.

4. Hui, P.; Tan, H.S. Temperature distributions in a heat dissipation system using a cylindrical diamond heat spreader on a copper heat sink. J. Appl. Phys. 1994, 75, 748-757.

5. Shidore, S.; Adams, V.; Lee, T.T. A study of compact thermal model topologies in CFD for a flip chip plastic ball grid array package. IEEE Trans. Compon. Packag. Technol. 2001, 24, 191-198.

6. Fleischer, A.S.; Weinstein, R.D.; Khobragade, S.A. Forced convective cooling of electro-optical components maintained at different temperatures on a vertically oriented printed circuit board. IEEE Trans. Compon. Packag. Technol. 2004, 27, 296-304.

7. Anders, G.J.; Radhakrishna, H.S. Power cable thermal analysis with consideration of heat and moisture transfer in the soil. IEEE Trans. Power Delivery 1988, 3, 1280-1288.

8. Paulke, J.; Weichert, H.; Steinhaeuser, P. Thermal simulation of switchgear. IEEE Trans. Compon. Packag. Technol. 2002, 25, 434-439.

(C) 2011 by the authors; licensee MDPI, Basel, Switzerland. This article is an open access article distributed under the terms and conditions of the Creative Commons Attribution license (http://creativecommons.org/licenses/by/3.0/). 